\title{
RESTRICTION OF LIQUID WATER SPREADING IN OVERLAID PLYWOOD TOP VENEER
}

\author{
Dace Cirule $^{1}$, Edgars Kuka ${ }^{1,2}$, Anrijs Verovkinss ${ }^{1}$, Ingeborga Andersone ${ }^{1}$ \\ ${ }^{1}$ Lavian State Institute of Wood Chemistry, Latvia \\ ${ }^{2}$ Riga Technical University, Latvia \\ xylon@edi.lv
}

\begin{abstract}
Plywood overlaid with resin impregnated paper films is used in various decorative applications for which high stability of aesthetic qualities is of great importance. The top veneer of the plywood for these materials is perfectly protected from a direct contact with water as far as the covering film is not damaged. However, in case of film damage water can cause clearly visible defects in a relatively short period of time. To reduce these types of defects, unsophisticated and efficient way was developed. It involves filling the vessel system of the top veneer with industrial phenol-formaldehyde resin by using a hot-press. Influence of some phenol-formaldehyde resin properties on its penetration in birch veneer as well as the effect of wood moisture content were tested. The proposed top veneer pre-treatment method with phenol-formaldehyde resin reduced the average swelling zone distance from damage site by half for oven pre-dried plywood with 3\% moisture content before treatment. Moreover, it was found that using plywood with moisture content of $9 \%$ the swelling zone distance was reduced by two thirds compared to untreated overlaid plywood.
\end{abstract}

Key words: plywood; phenol-formaldehyde resin; water spreading.

\section{Introduction}

Plywood manufacturing from wood veneer layers by gluing them together with resins is one of the largest wood-based composite industries (Chang et al., 2018). In comparison with solid wood products, the design of plywood with veneer sheets glued together with adjacent layers having their wood grain perpendicular to one another results in reduced tendency of swelling and shrinking, providing improved dimensional stability in changing humidity environment. Moreover, such a design makes the plywood panel less anisotropic regarding its strength properties. Different varieties of plywood have been designed and are manufactured for multitude of applications such as furniture, engineering constructions, vehicles, sporting goods and equipment, packaging, ships and yachts and others (Hrázský \& Král, 2007). Among others, plywood overlaid with a resin impregnated paper film has gained its niche for various decorative applications. Mostly melamine and phenolic resins are used for production of resin films, which are subsequently hot-pressed onto one or both of plywood sheet surfaces. Beside changed appearance, covering of plywood with resin-impregnated film significantly improves water and abrasion/wear resistance as well as facilitates cleaning and maintenance of the surface. Moreover, the resin film coating perfectly protects the top veneer of plywood from a direct contact with water as long as the covering film is intact. However, in case of the film damage, the inherent wood swelling characteristics can provoke noticeable surface failure even after a relatively short contact with water.

Intensive research has been done and is still under experimentation to overcome the high moisture sensitiveness of wood thus improving its utility. There are numerous modification processes proposed to reduce wood swelling, which can be divided into two groups: an active modification involving changes in wood chemical structure and passive modification, which does not alter the chemistry of wood (Hill, 2006; Epmeier, Westin, \& Rapp, 2004; Sandberg, Kutnar, \& Mantanis, 2017). The active modification of wood comprises wood treatment methods, which are quite sophisticated and therefore costly, such as thermal modification, acetylation, furfurilation. Besides, wood modification through alteration of its chemical structure often involves reduction of strength properties (Epmeier, Westin, \& Rapp, 2004). Passive modification mainly is performed by impregnation with an aim to bulk the wood cell wall thus preventing dimensional changes of wood caused by varying humidity conditions or direct contact with liquid water. It is found that water-soluble low molecular weight phenol-formaldehyde $(\mathrm{PF})$ resins can penetrate into a wood cell wall and improve wood dimensional stability (Seborg, Tarkow, \& Stamm, 1962; Furuno, Imamura, \& Kajita, 2004; Kielmann, Butter, \& Mai, 2018). However, even a very high resin loadings cannot totally prevent dimensional changes of wood (Hill, 2006). Another type of passive impregnation involves cell lumens filling. It cannot prevent swelling but can substantially hinder liquid water spreading through the wood porous structure. In such a way, the region subjected to action of water is reduced.

The flow of liquid primarily moves in the path of least resistance. In hardwoods, the least resistance path is the capillary structure of vessel network, which is characterized by relatively wide lumens and end-to-end connection with perforation plates of high permeability (Kamke \& Lee, 2007). The penetration 
rate of liquid into wood varies depending on both the wood structure and properties and the characteristics of the penetrant solution (Meijer, Thurich, \& Militz, 2001; Meijer, 2004; Kučerová, 2012). It implies that filling of vessel lumens could hinder fast water spreading into the top veneer under damaged covering film thus reducing the surface area subjected to swelling and lessening the visual defects.

The present study was aimed at finding an unsophisticated and effective way for the enhancement of covered plywood resistance to rapid local swelling in case of top veneer contact with water because of the covering film damage.

\section{Materials and Methods}

All of the materials used for experiments were supplied by JSC 'Latvijas Finieris'. Plywood overlaid with PF resin impregnated film was used to determine the swelling zone expansion rate from the damaged site. The damaged site was created by drilling in the surface of the overlaid plywood an approximately 5 $\mathrm{mm}$ deep hole with diameter of $2.8 \mathrm{~mm}$. Afterwards the damaged site was exposed to liquid water and the swelling zone distance was measured after certain periods of time (10, 30, 60, 120, 240 and $1440 \mathrm{~min})$ with an accuracy of $1 \mathrm{~mm}$.

Partly polymerised PF resin was obtained by heating the industrial PF resin in water bath for $3 \mathrm{~h}$ at $50 \pm 1^{\circ} \mathrm{C}$. Partly dehydrated PF resin was obtained from the industrial PF resin by using a rotary vacuum evaporator with process parameters: vacuum - 30 mbar, temperature $-20^{\circ} \mathrm{C}$, rotation speed $-100 \mathrm{rpm}$. To obtain $\mathrm{PF}$ resins with a different water content, dehydration was performed for $1 \mathrm{~h}, 2 \mathrm{~h}$ and $4 \mathrm{~h}$. Viscosity of the PF resins was measured by using rotational viscometer HAAKE Viscotester 6 plus. The water content of the $\mathrm{PF}$ resins was determined by drying the $\mathrm{PF}$ resin ( 2 g) in an oven at $140{ }^{\circ} \mathrm{C}$ for $1 \mathrm{~h}$. The mass of PF resin was weighed before and after drying. From these measurements the mass loss (water content) was calculated assuming that only water evaporates.

Rotary-cut birch (Betula spp.) veneers with thickness $1.4 \mathrm{~mm}$ were used for impregnation with the industrial PF resin as well as with the resins modified by polymerization and dehydration. The set of six veneer specimens with dimensions $100 \times 100 \mathrm{~mm}$ per each resin type was used for impregnation. The impregnation was carried out under vacuum (22 mbar) for $10 \mathrm{~min}$. The excess of resin was wiped off from the veneer surface with a paper towel immediately after removing the specimens from the impregnation container. To polymerize the impregnated resin, the specimens were kept in an oven $\left(140 \pm 2{ }^{\circ} \mathrm{C}\right)$ for 12 $\mathrm{h}$ and weight percent gain (WPG) was calculated as a percentage increase of the dry weight of the specimens after the impregnation.
To evaluate how the water content of the industrial PF resin is changed after spreading it over the plywood surface depending on the wood moisture content, an equal amount of PF resin was paintbrush applied on three surfaces (100 $\mathrm{cm}^{2}$ surface area): aluminium plate (as control), conditioned plywood (RH $65 \pm 5 \%$, temperature $20 \pm 2{ }^{\circ} \mathrm{C}$ ) with $9 \%$ moisture content and oven pre-dried $\left(102 \pm 3^{\circ} \mathrm{C}\right)$ plywood with $3 \%$ moisture content. After five and ten minutes the PF resin was removed with a scraper and the water content was determined as previously described. The control was used to exclude from the calculations the water that evaporates during exposure for 5 and $10 \mathrm{~min}$.

To assess the effect of the top veneer pretreatment with $\mathrm{PF}$ resin on reducing of the rapid swelling zone of the overlaid plywood, PF resin was applied with a paintbrush onto the plywood surface (amount: 120 - $140 \mathrm{~g} \mathrm{~m}^{-2}$ ) prior to the covering film hot-pressing process. Manufacturing of overlaid plywood specimens was performed in a laboratory by using hydraulic laboratory press. To manufacture the specimens, plywood with pre-treated top veneer was covered with a PF resin impregnated film and pressed under $1.9 \mathrm{MPa}$ pressure for $5 \mathrm{~min}$ at $140{ }^{\circ} \mathrm{C}$ temperature.

To assess resin distribution in the top layer of the pre-treated plywood, $1 \mathrm{~cm}$ wide bars were sawn from specimen central parts and, after softening by boiling in water for $3 \mathrm{~h}$, samples were sliced for a light microscopy examination. The examination was performed with a transmitted light microscope "Leica DMLB” connected to the video camera „Leica DFC490".

\section{Results and Discussion}

The results of the experiment in which the rate of the swelling zone expansion was evaluated show that liquid water transport in the top veneer is relatively rapid and the covered distance can be quite large. The average distance from the site of damage to the end of the swelling zone after 24 hours (1440 min) was $32 \pm$ $7 \mathrm{~cm}$. Moreover, more than $60 \%$ of the total swelling zone distance was reached during the first 30 minutes. The development of the swelling zone from damage site during the first four hours after artificial swelling initiation is presented in Figure 1.

The results show that the damage site can cause a fast development of swelling zone on the surface of the overlaid plywood when in contact with liquid water. Besides, the results show that there is a limit how far the swelling zone can develop from the damage site, and the distance depends on the site's specific wood anatomic structure. The main cause of the fast development of the swelling defects is attributed to the rapid liquid water transport through the birch wood vessel system. Therefore, the restriction of water flow 


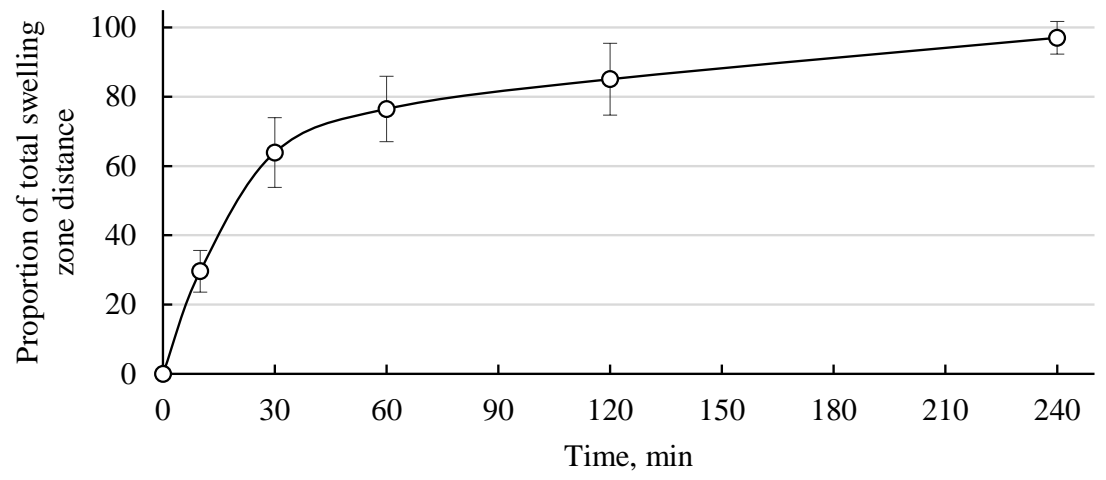

Figure 1. Development of swelling zone from the damage site on overlaid plywood.

Error bars represent standard deviations.

by filling the vessels with PF resin could be one of the possibilities to reduce or eliminate the formation of such aesthetic defects.

To evaluate the possibility of filling birch wood vessels with $\mathrm{PF}$ resin and to estimate the effect of resin properties on this process, vacuum impregnation of birch veneers for $10 \mathrm{~min}$ was performed. The resin penetration was evaluated by measuring the weight percent gain (WPG) of the impregnated birch veneer and the results are presented in Table 1.

The results show that the resin penetration into birch veneers is significantly affected by the resin properties and the largest influence is attributed to the resin viscosity. By increasing the phenolformaldehyde resin temperature by $10{ }^{\circ} \mathrm{C}$, which resulted in a decrease of resin viscosity by $43 \%$, the WPG increased twice reaching the average value of $26.4 \%$. Also, for partly polymerised PF resin the WPG significantly increased by rising the resin temperature by $20^{\circ} \mathrm{C}$ which caused decrease in resin viscosity by $47 \%$. Moreover, partial polymerisation of the resin reduced its ability to penetrate into the birch veneer. However, it was still possible to achieve high WPG (34.9\%) by increasing the temperature of the partly polymerised resin. For partly dehydrated
PF resin, the WPG values were the lowest from all the tested resin types. As the dehydration was performed in vacuum without increased temperature, no substantial polymerisation of resin is supposed to occur. Therefore, inability of partly dehydrated resin to penetrate into veneer is mainly attributed to the very high resin viscosity due to reduced water content. These results suggest that viscosity is highly important regarding the resin penetration into wood and therefore should be well analysed. Meijer (2004) in his review paper concluded that penetration capacity of coating is mainly attributed to the viscosity, which is in agreement with the results of the present study. In addition, he concluded that wetting and surface tension of the coating seem to play only a minor role.

As previously shown, a partial dehydration of $\mathrm{PF}$ resin can cause a significant increase in resin viscosity that results in low WPG of the impregnated birch veneer. Therefore, it is important to determine how water content of phenol-formaldehyde resin influences the resin viscosity. The results of the experiment are presented in Figure 2. The PF resin dehydrated for 4 $\mathrm{h}$ is not included in the figure because its viscosity at $20^{\circ} \mathrm{C}$ was too high for measuring with the viscometer used in the study.

Effect of phenol-formaldehyde resin properties on resin penetration

Table 1 in birch veneer by vacuum impregnation

\begin{tabular}{|l|c|c|c|}
\hline \multicolumn{1}{|c|}{ Industrial resin type } & $\begin{array}{c}\text { Resin } \\
\text { temperature } \\
(\mathrm{T}),{ }^{\circ} \mathrm{C}\end{array}$ & $\begin{array}{c}\text { Resin } \\
\text { viscosity, } \\
\mathrm{mPa} \mathrm{s}\end{array}$ & $\begin{array}{c}\text { Veneer average weight } \\
\text { percent gain after } \\
\text { impregnation, \% }\end{array}$ \\
\hline Industrial phenol-formaldehyde resin & 20 & 212 & $13.4(3.4)$ \\
\hline Industrial phenol-formaldehyde resin & 30 & 120 & $26.4(4.7)$ \\
\hline Partly polymerised phenol-formaldehyde resin & 30 & 180 & $6.5(3.8)$ \\
\hline Partly polymerised phenol-formaldehyde resin & 50 & 96 & $34.9(9.9)$ \\
\hline Partly dehydrated (4 h) phenol-formaldehyde resin & 65 & 2600 & $4.7(1.6)$ \\
\hline
\end{tabular}

Standard deviation in parentheses 


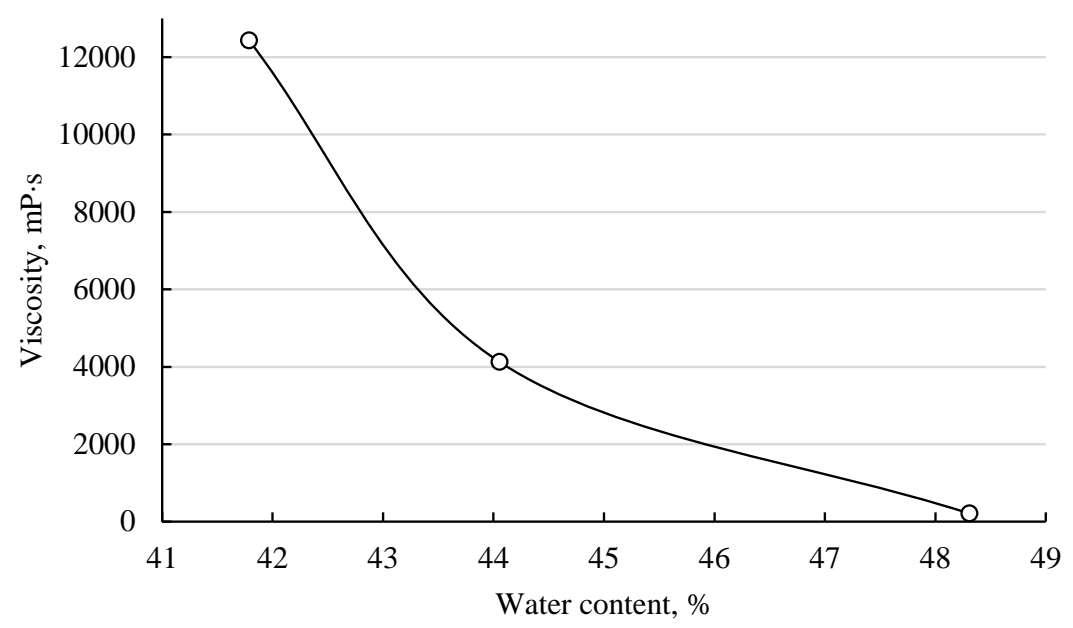

Figure 2. Effect of phenol-formaldehyde resin water content on resin viscosity at $20^{\circ} \mathrm{C}$.

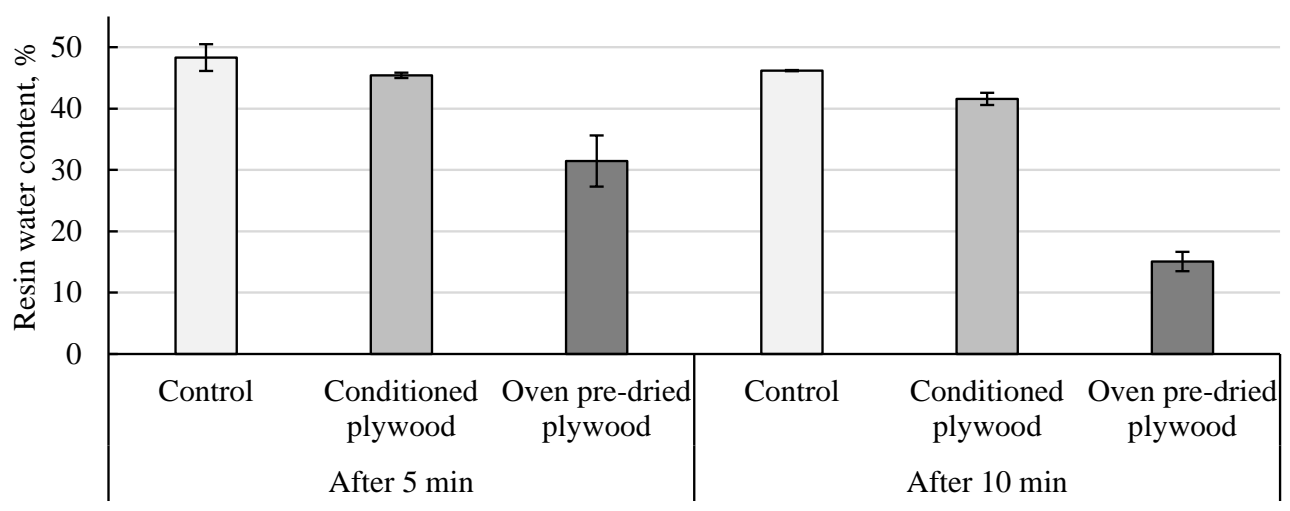

Figure 3. Water content of phenol-formaldehyde resin after application on plywood surface. Error bars represent standard deviations.

The results clearly show that water presence in PF resin is highly important to ensure appropriate resin viscosity for efficient resin penetration. The resin viscosity increased more than 20 times when the water content of the resin was reduced by only $6 \%$ (from $48 \%$ to $42 \%)$. A similar trend has been observed for urea-formaldehyde and polyvinyl acetate adhesives (Hass et al., 2012). The results suggest that any loss of water content of PF resin could be crucial in the process of filling wood vessels.

By using resin pre-treatment, it is possible that plywood with low moisture content due to its inherent hydrophilic nature could remove some of the water from $\mathrm{PF}$ resin before the resin itself can penetrate into the vessels, which subsequently would result in higher resin viscosity and hindered penetration into wood. Therefore, the wood moisture content effect on removal of water from the PF resin was tested. The results are presented in Figure 3.

The results show that a significant decrease in water content of PF resin is noticeable due to wood ability to absorb water. After 5 min water content of the resin decreased by $6 \%$ and $35 \%$, but after 10 min by $10 \%$ and $67 \%$ compared to the control for conditioned (moisture content 9\%) and oven predried (moisture content 3\%) plywood, respectively. In case of oven pre-dried plywood, such changes in water content of resin can dramatically affect further resin penetration in wood vessels because of the enormous increase in resin viscosity. These results are in accordance with the studies in which similar tendencies have been established regarding glue and water-borne paint penetration into wood depending on the wood moisture content (Hrázský \& Král, 2007; Meijer, Thurich, \& Militz, 2001).

Several overlaid plywood specimens were produced and the swelling zone from artificiallycreated damage site was measured to test how addition of PF resin between the plywood surface and PF impregnated film can affect the average distance of the swelling zone. The results are presented in Figure 4.

An addition of PF resin significantly reduces the average swellings zone distance from the damaged site on the overlaid plywood surface. Moreover, the results 


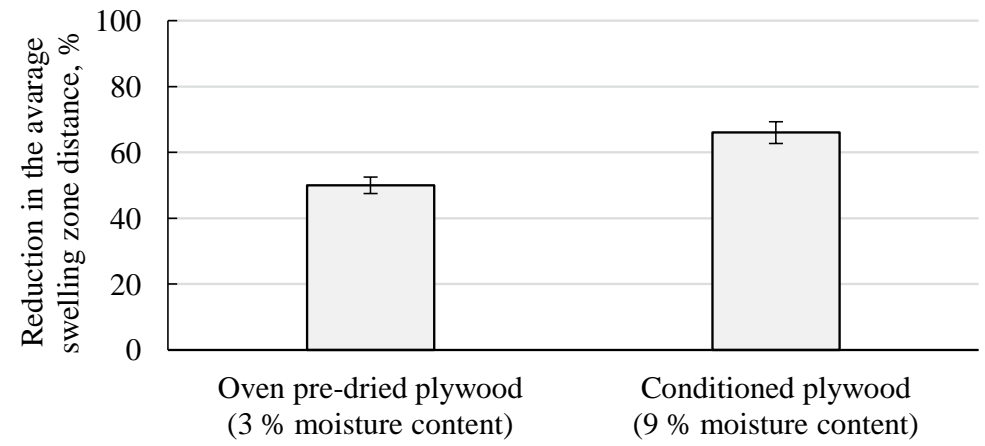

Figure 4. Effect of phenol-formaldehyde resin pre-treatment and plywood moisture content on reduction of the average swelling zone distance from the damage site. Error bars represent standard deviations.
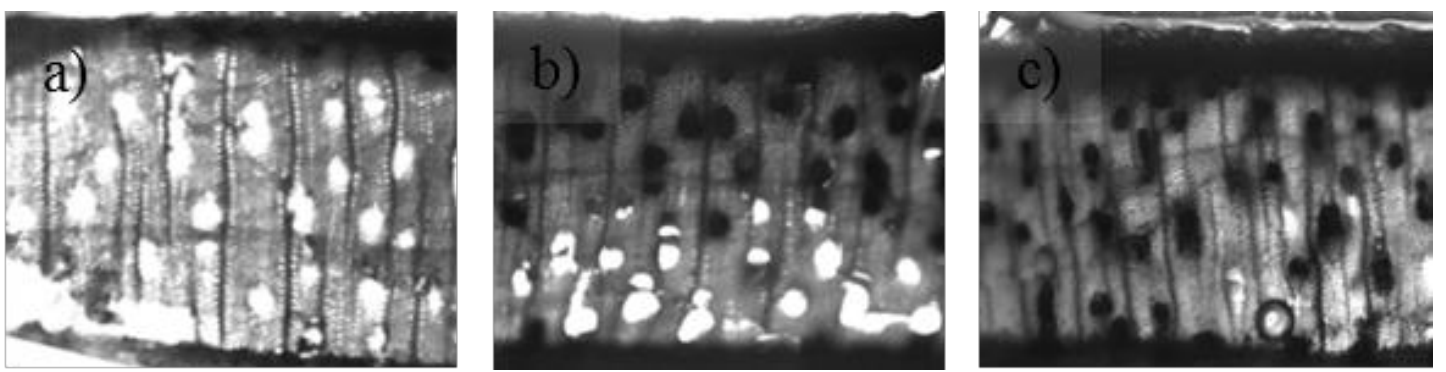

Figure 5. Top veneer cross sections of overlaid birch plywood pre-treated with phenol-formaldehyde resin: a) empty vessel lumens; b) part of vessel lumens filled; c) completely filled vessel lumens.

for conditioned plywood with $9 \%$ moisture content were better than for the oven pre-dried plywood with $3 \%$ moisture content, which is in accordance with previously discussed results about the wood ability to absorb water from PF resin depending on the wood moisture content. The examination of the top veneer cross-sections with microscope showed that the reduction in the average swelling zone distance is mainly due to PF resin penetration into wood vessels, which restricts rapid liquid water transport in top veneer of the overlaid plywood. These results suggest that for more efficient filling of birch wood vessels with PF resin and subsequent restriction of water spreading, the plywood moisture is of a great importance and the plywood of the highest admissible moisture content regarding the technological process should be used in order to ensure top veneer with reduced water transportation ability.

However, in Figure 5 presented light microscopy images of specimens prepared from one plywood sample pre-treated with PF resin show that PF resin penetration in birch wood vessels can be rather uneven. The area with all vessel lumens empty (a), area with only part of lumens filled (b), and the area with completely filled vessel lumens (c) were detected even within one specimen in some cases. The inhomogeneous resin penetration in wood vessels could be partly attributed to the differences in wood anatomy (Meijer, 2004). This can account for only reduction and not complete elimination of fast water spreading into the top veneer of plywood with damaged covering film by using the proposed method.

\section{Conclusions}

1. The damage of overlaid plywood covering film in presence of liquid water causes a rapid formation and spreading of well noticeable swelling zone and during the first 30 minutes more than $60 \%$ of the total swelling zone is reached.

2. Resin viscosity significantly affect its penetration ability into veneer. Reduction of the water content of phenol-formaldehyde resin causes an increase in viscosity which hinders resin penetration into wood.

3. The best penetration of the resin into veneer was achieved for specimens with a higher moisture content, which is in accordance with the findings that wood readily absorbs water from resin and the absorption capacity is inversely related to wood moisture content.

4. In the present study, a method for the enhancement of covered plywood resistance to rapid local swelling was developed comprising pre-treatment of top veneer with phenol-formaldehyde resin to fill wood vessels followed by hot-pressing of covering film. 
5. The results showed that by applying the proposed method it is possible to restrict liquid water spreading and subsequently reduce the total average swelling zone distance from the damage site by half.

\section{Acknowledgements}

The authors gratefully acknowledge the financial support by the European Regional Development Fund in the framework of the "Forest Sector Competence Centre" project "Wood based composites with improved properties" (No 1.2.1.1/16/A/009)

\section{References}

1. Chang, L., Tang, Q., Gao, L., Fang, L., Wang, Z., \& Guo, W. (2018). Fabrication and characterization of HDPE resins as adhesives in plywood. Eur.J.Wood Prod. 76, 325-335. DOI: 10.1007/s00107-016-1117-z.

2. Epmeier, H., Westin, M., \& Rapp, A. (2004). Differently modified wood: Comparison of some selected properties. Scand. J. For. Res. 19, 31-37. DOI: 10.1080/02827580410017825.

3. Furuno, T., Imamura, Y., \& Kajita, H. (2004). The modification of wood by treatment with low molecular weight phenol-formaldehyde resin: a properties enhancement with neutralized phenolic-resin and resin penetration into wood cell walls. Wood Sci. Technol. 37, 349-361. DOI: 10.1007/s00226-003-0176-6.

4. Hass, P., Wittel, F.K., Mendoza, M., Herrmann, H.J., \& Niemz, P. (2012). Adhesive penetration in beech wood: experiments. Wood Sci. Technol. 46, 243-256. DOI: 10.1007/s00226-011-0410-6.

5. Hill, C.A.S. (2006). Wood Modification: Chemical, Thermal, and Other Processe, West Sussex, England: John Willey \& Sons Ltd.

6. Hrázský, J., \& Král, P. (2007). Determination of the pressing parameters of spruce water-resistant plywood. Journal of Forest Science. 53(5), 231-242.

7. Kamke, F.A., \& Lee, J.N. (2007). Adhesive penetration in wood - a review. Wood and Fiber Science. 39(2), 205-220.

8. Kielmann, B.C., Butter, K., \& Mai, C. (2018). Modification of wood with formulations of phenolic resin and iron-tannin-complexes to improve material properties and expand colour variety. Eur. J. Wood Prod. 76, 259-267. DOI: 10.1007/s00107-017-1180-0.

9. Kučerová, I. (2012). Methods to measure the penetration of consolidant solutions into 'dry' wood. Journal of Cultural Heritage. 13S, S191-S195. DOI: 10.1016/j.culher.2012.04.012.

10. Meijer, M. (2004). A review of interfacial aspects in wood coatings: wetting, surface energy, substrate penetration and adhesion. In European Seminar on High Performance Wood Coatings, Exterior and Interior Performance, 26-27 April 2004 (pp. 1-16). Paris, France.

11. Meijer, M., Thurich, K., \& Militz, H. (2001). Quantitative measurements of capillary coating penetration in relation to wood and coating properties. Holz als Roh- und Werkdtoff. 59, 35-45. DOI: 10.1007/ s001070050469.

12. Sandberg, D., Kutnar, A., \& Mantanis, G. (2017). Wood modification technologies - a review. iForest. 10, 895-908. DOI: 10.3832/ifor2380-010.

13. Seborg, R.M., Tarkow, H., \& Stamm, A.J. (1962). Modified woods. FPL Report No. 2192 (revised. Originally published by Stamm, A.J. in the 1948 edition of Modern Plastics Encyclopedia), 30 pp. 